\title{
8 Neural Representation of Fat Texture in the Mouth
}

\author{
Edmund T. Rolls
}

\section{CONTENTS}

$8.1 \quad$ Summary

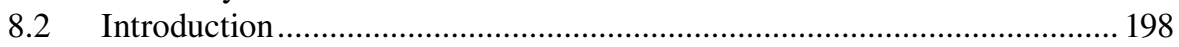

8.3 Taste Processing in the Primate Brain ........................................................... 199

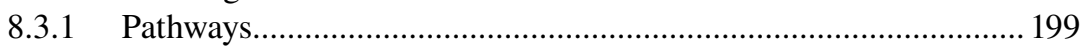

8.3.2 The Primary Taste Cortex ........................................................200

8.3.3 The Secondary Taste Cortex.......................................................200

8.3.4 Five Prototypical Tastes, Including Umami .................................200

8.3.5 The Pleasantness of the Taste of Food...........................................200

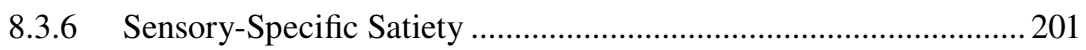

8.4 The Representation of Flavor: Convergence of Olfactory

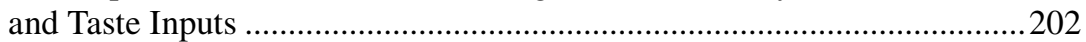

8.5 The Representation of the Pleasantness of Odor in the Brain: Olfactory and Visual Sensory-Specific Satiety, Their Representation in the Primate Orbitofrontal Cortex, and the Role of Sensory-Specific Satiety in Appetite.

8.6 The Responses of Orbitofrontal Cortex Taste and Olfactory Neurons to the Sight, Texture, and Temperature of Food ........................................... 203

8.7 The Mouthfeel of Fat: Orbitofrontal Cortex, Primary Taste Cortex,

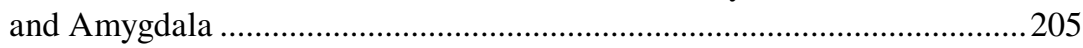

8.8 Activation of the Human Brain by Oral Signals, Including Fat Texture ......................................................................... 212

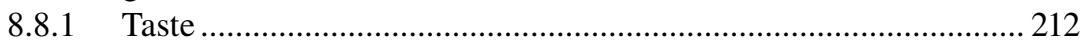

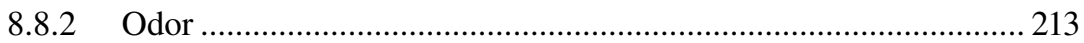

8.8.3 Olfactory-Taste Convergence to Represent Flavor,

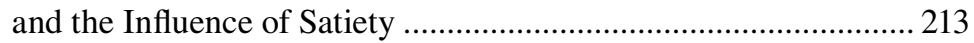

8.8.4 Oral Viscosity and Fat Texture ....................................................... 214

8.8.5 The Pleasantness of the Flavor of Food........................................ 217 


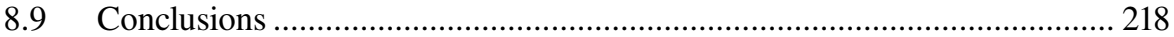

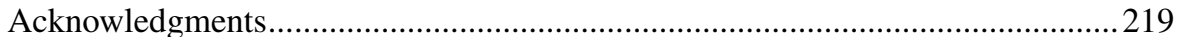

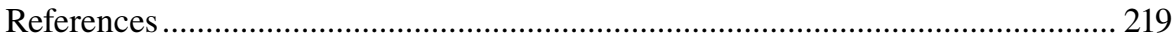

\subsection{SUMMARY}

The brain areas that represent taste also provide a representation of oral texture. Fat texture is represented by neurons independently of viscosity: some neurons respond to fat independently of viscosity, and other neurons encode viscosity. The neurons that respond to fat also respond to silicone oil and paraffin oil, indicating that the sensing is not chemospecific, but is instead based on texture. This fat sensing is not related to free fatty acids (FFA), in that these neurons typically do not respond to FFA such as linoleic acid (LiA). Moreover, a few neurons with responses to FFA typically do not respond to fat in the mouth. Fat texture-sensitive neurons are found in the primary taste cortex in the rostral insula and adjoining frontal operculum, in the secondary taste cortex in the orbitofrontal cortex, and in the amygdala. In these regions, the fat texture responsiveness of these neurons may be combined with taste and/or oral temperature responses, and in the orbitofrontal cortex with olfactory responses. Different neurons respond to different combinations, providing a rich representation of the sensory properties of food. In the orbitofrontal cortex, feeding to satiety with one food decreases the responses of these neurons to that food, but not to other foods, showing that sensory-specific satiety and appetite modulation are represented in the orbitofrontal cortex. A complementary functional neuroimaging study in humans showed activation by fat in the mouth of the insula, orbitofrontal cortex, and a region to which it projects, the pregenual cingulate cortex. In summary, one way in which fat in the mouth is represented in the brain is by its texture, and an indication of what must be transduced has been provided by these neuroscience studies.

\subsection{INTRODUCTION}

The aim of this chapter is to describe how fat in the mouth is represented in the brain. This is an important issue, for it is not yet clear how oral fat is sensed, and evidence from neuroscience is providing indications about this. Moreover, fat in the diet may be pleasant, yet its intake must be controlled, and understanding the rules by which the pleasantness of fat is regulated is important. In addition, the brain's representation of oral fat is frequently in terms of particular combinations with other sensory aspects of food, including taste, texture, and olfactory inputs, and these combinations are important for understanding the full impact of fat in the mouth on the pleasantness of food.

Because the representation of fat in the mouth is closely linked to taste processing in the brain, we start with an overview of taste pathways and processing in the brain, before we consider how oral fat is represented in the same brain areas, and frequently but not always in combination with taste. To make the results relevant to understanding the control of human food intake, complementary evidence is provided by neurophysiological studies in nonhuman primates in which the taste and 
related pathways are similar to those in humans, and by functional neuroimaging studies in humans. A broad perspective on brain processing involved in hedonic aspects of the control of food intake and in affective responses more generally is provided by Rolls (2005).

\subsection{TASTE PROCESSING IN THE PRIMATE BRAIN}

\subsubsection{Pathways}

A diagram of the taste and related olfactory, somatosensory, and visual pathways in primates is shown in Figure 8.1. The multimodal convergence that enables single neurons to respond to different combinations of taste, olfactory, texture, temperature, and visual inputs to represent different flavors produced often by new combinations of sensory input is afforded by the convergence of processing pathways evident in brain areas such as the orbitofrontal cortex (Rolls, 2007; Rolls and Grabenhorst, 2008).

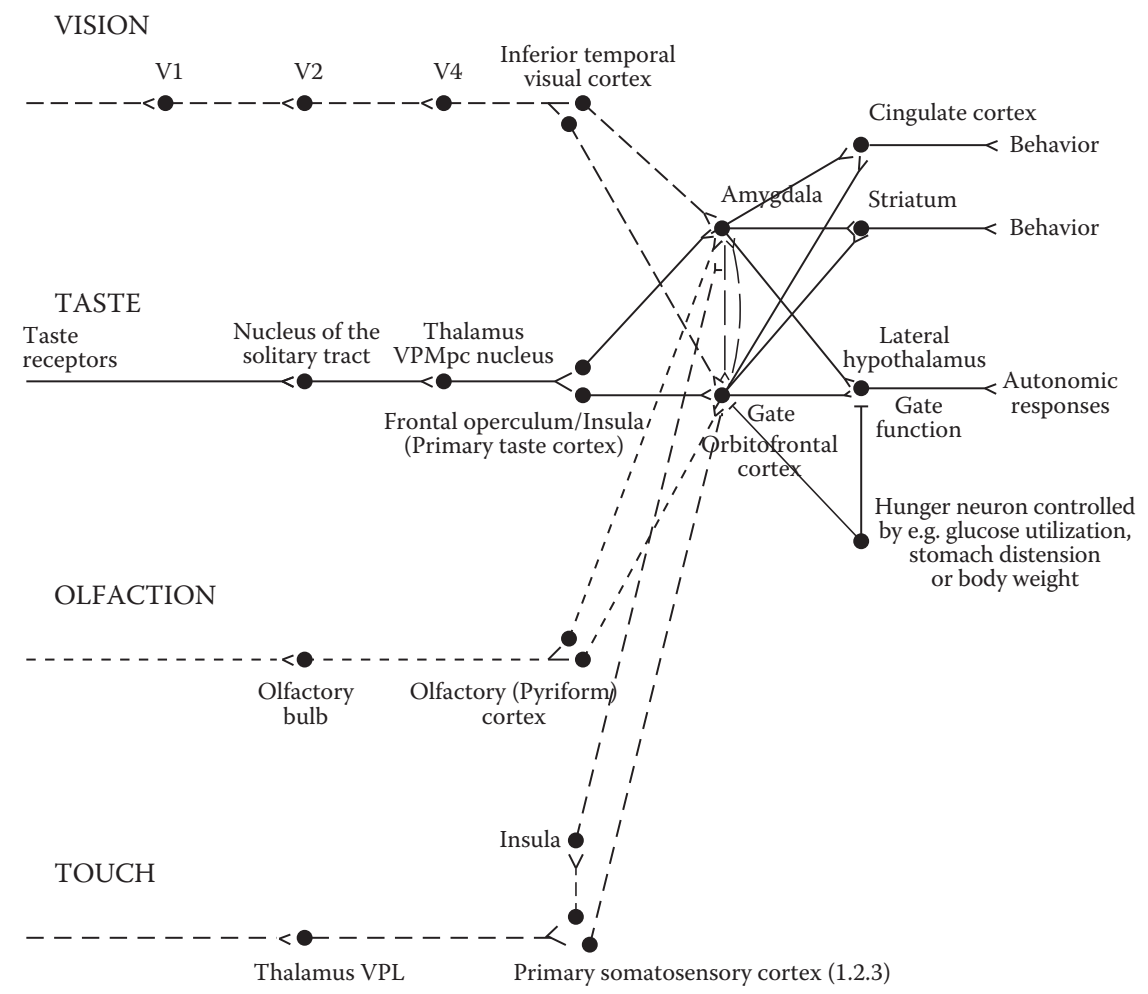

FIGURE 8.1 Schematic diagram of the taste and olfactory pathways in primates including humans showing how they converge with each other and with visual pathways. Hunger modulates the responsiveness of the representations in the orbitofrontal cortex of the taste, smell, texture, and sight of food (indicated by the gate function), and the orbitofrontal cortex is where the palatability and pleasantness of food is represented. VPMpc, ventralposteromedial thalamic nucleus; V1, V2, V4, visual cortical areas. 


\subsubsection{The Primary Taste Cortex}

The primary taste cortex in the primate anterior insula and adjoining frontal operculum contains not only taste neurons tuned to sweet, salt, bitter, sour (Scott et al., 1986; Yaxley et al., 1990; Rolls and Scott, 2003), and umami as exemplified by monosodium glutamate (MSG) (Baylis and Rolls, 1991; Rolls et al., 1996b), but also other neurons that encode oral somatosensory stimuli including viscosity, fat texture, temperature, and capsaicin (Verhagen et al., 2004). Some neurons in the primary taste cortex respond to particular combinations of taste and oral texture stimuli, but do not respond to olfactory stimuli or visual stimuli such as the sight of food (Verhagen et al., 2004). Neurons in the primary taste cortex do not represent the reward value of taste, that is the appetite for a food, in that their firing is not decreased to zero by feeding the taste to satiety (Rolls et al., 1988; Yaxley et al., 1988).

\subsubsection{The Secondary Taste Cortex}

A secondary cortical taste area in primates was discovered by Rolls et al. (1990) in the caudolateral orbitofrontal cortex, extending several millimeters in front of the primary taste cortex. One principle of taste processing is that by the secondary taste cortex, the tuning of neurons can become quite specific, with some neurons responding, for example, only to sweet taste. This specific tuning (especially when combined with olfactory inputs) helps to provide a basis for changes in appetite for some but not other foods eaten during a meal.

\subsubsection{Five Prototypical Tastes, Including Umami}

In the primary and secondary taste cortices, there are many neurons that respond best to each of the four classical prototypical tastes: sweet, salt, bitter, and sour (Rolls, 1997; Rolls and Scott, 2003), but also there are many neurons that respond best to umami tastants such as glutamate (which is present in many natural foods such as tomatoes, mushrooms, and milk) (Baylis and Rolls, 1991) and inosine monophosphate (which is present in meat and some fish such as tuna) (Rolls et al., 1996b). This evidence, taken together with the identification of possible glutamate taste receptors (Zhao et al., 2003; Maruyama et al., 2006), leads to the view that there are five prototypical types of taste information channels, with umami contributing, often in combination with corresponding olfactory inputs (Rolls et al., 1998; McCabe and Rolls, 2007), to the flavor of protein. In addition, other neurons respond to water, and others to somatosensory stimuli including astringency as exemplified by tannic acid (Critchley and Rolls, 1996b), and capsaicin (Rolls et al., 2003b; Kadohisa et al., 2004).

\subsubsection{The Pleasantness of the Taste of Food}

The modulation of the reward value of a sensory stimulus such as the taste of food by motivational state, for example hunger, is one important way in which motivational behavior is controlled (Rolls, 1999, 2005). The subjective correlate of this modulation is that food tastes pleasant when hungry, and tastes hedonically neutral when it 
has been eaten to satiety. We have found that the modulation of taste-evoked signals by motivation is not a property found in early stages of the primate gustatory system. The responsiveness of taste neurons in the nucleus of the solitary tract (Yaxley et al., 1985) and in the primary taste cortex (frontal opercular, Rolls et al., 1988; insular, Yaxley et al., 1988) is not attenuated by feeding to satiety. In contrast, in the secondary taste cortex, in the caudolateral part of the orbitofrontal cortex, it has been shown that the responses of the neurons to the taste of glucose decreased to zero while the monkey ate it to satiety, during the course of which the behavior turned from avid acceptance to active rejection (Rolls et al., 1989). This modulation of responsiveness of the gustatory responses of the orbitofrontal cortex neurons by satiety could not have been due to peripheral adaptation in the gustatory system or to altered efficacy of gustatory stimulation after satiety was reached, because modulation of neuronal responsiveness by satiety was not seen at the earlier stages of the gustatory system, including the nucleus of the solitary tract, the frontal opercular taste cortex, and the insular taste cortex.

\subsubsection{Sensory-Specific Satiety}

In the secondary taste cortex, it was also found that the decreases in the responsiveness of the neurons were relatively specific to the food with which the monkey had been fed to satiety (Rolls et al., 1989; Critchley and Rolls, 1996c).

This evidence shows that the reduced acceptance of food which occurs when food is eaten to satiety, and the reduction in the pleasantness of its taste (Cabanac, 1971; Rolls and Rolls, 1977, 1982; Rolls et al., 1981a,b, 1982, 1983a), are not produced by a reduction in the responses of neurons in the nucleus of the solitary tract or frontal opercular or insular gustatory cortices to gustatory stimuli. Indeed, after feeding to satiety, humans reported that the taste of the food on which they had been satiated tasted almost as intense as when they were hungry, though much less pleasant (Rolls et al., 1983b).This comparison is consistent with the possibility that activity in the frontal opercular and insular taste cortices as well as the nucleus of the solitary tract does not reflect the pleasantness of the taste of a food, but rather its sensory qualities independently of motivational state. On the other hand, the responses of the neurons in the caudolateral orbitofrontal cortex taste area and in the lateral hypothalamus (Rolls et al., 1986) are modulated by satiety, and it is presumably in areas such as these that neuronal activity may be related to whether a food tastes pleasant, and to whether the food should be eaten (see further Scott et al., 1995; Critchley and Rolls, 1996a; Rolls, 1996, 1999, 2000a,b; Rolls and Scott, 2003). In addition to providing an implementation of sensory-specific satiety (probably by habituation of the synaptic afferents to orbitofrontal neurons with a time course of the order of the length of a course of a meal), it is likely that visceral and other satiety-related signals reach the orbitofrontal cortex (as indicated in Figure 8.1) (from the nucleus of the solitary tract, via thalamic nuclei) and there modulate the representation of food, resulting in an output that reflects the reward (or appetitive) value of each food (Rolls, 2005).

It is an important principle that the identity of a taste, and its intensity, are represented separately from its pleasantness (Grabenhorst and Rolls, 2008; Grabenhorst 
et al., 2008). Thus it is possible to represent what a taste is, and to learn about it, even when we are not hungry.

\subsection{THE REPRESENTATION OF FLAVOR: CONVERGENCE OF OLFACTORY AND TASTE INPUTS}

At some stage in taste processing, it is likely that taste representations are brought together with inputs from different modalities, for example, with olfactory inputs to form a representation of flavor (see Figure 8.1). We found (Rolls and Baylis, 1994) that in the orbitofrontal cortex taste areas, of 112 single neurons which responded to any of these modalities, many were unimodal (taste $34 \%$, olfactory $13 \%$, and visual $21 \%$ ), but were found in close proximity to each other. Some single neurons showed convergence, responding, for example, to taste and visual inputs (13\%), taste and olfactory inputs (13\%), and olfactory and visual inputs (5\%). Some of these multimodal single neurons had corresponding sensitivities in the two modalities, in that they responded best to sweet tastes (e.g., $1 \mathrm{M}$ glucose), and responded more in a visual discrimination task to the visual stimulus which signified sweet fruit juice than to that which signified saline; or responded to sweet taste, and in an olfactory discrimination task to fruit odor. The different types of neurons (unimodal in different modalities, and multimodal) were frequently found close to one another in tracks made into this region, consistent with the hypothesis that the multimodal representations are actually being formed from unimodal inputs to this region.

It thus appears to be in these orbitofrontal cortex areas that flavor representations are built, where flavor is taken to mean a representation which is evoked best by a combination of gustatory and olfactory input. This orbitofrontal region does appear to be an important region for convergence, for there is only a low proportion of bimodal taste and olfactory neurons in the primary taste cortex (Rolls and Baylis, 1994; Verhagen et al., 2004).

The bimodal neurons appear to be built by learning. Critchley and Rolls (1996a) showed that $35 \%$ of orbitofrontal cortex olfactory neurons categorized odors based on their taste association in an olfactory-to-taste discrimination task. Rolls et al. (1996b) found that $68 \%$ of orbitofrontal cortex odor-responsive neurons modified their responses in some way following changes in the taste reward associations of the odorants during olfactory taste discrimination learning and its reversal. (In an olfactory discrimination experiment, if a lick response to one odor, the $\mathrm{S}+$, is made a drop of glucose taste reward is obtained; if incorrectly a lick response is made to another odor, the $\mathrm{S}-$, a drop of aversive saline is obtained. At some time in the experiment, the contingency between the odor and the taste is reversed, and when the "meaning" of the two odors alters, so does the behavior. It is of interest to investigate in which parts of the olfactory system the neurons show reversal, for where they do, it can be concluded that the neuronal response to the odor depends on the taste with which it is associated, and does not depend primarily on the physicochemical structure of the odor.) These findings demonstrate directly a coding principle in primate olfaction whereby the responses of some orbitofrontal cortex olfactory neurons are modified by, and depend upon, the taste with which the odor is associated (Rolls, 2001, 2002a,b). 


\subsection{THE REPRESENTATION OF THE PLEASANTNESS OF ODOR IN THE BRAIN: OLFACTORY AND VISUAL SENSORY-SPECIFIC SATIETY, THEIR REPRESENTATION IN THE PRIMATE ORBITOFRONTAL CORTEX, AND THE ROLE OF SENSORY-SPECIFIC SATIETY IN APPETITE}

It has also been possible to investigate whether the olfactory representation in the orbitofrontal cortex is affected by hunger, and thus whether the pleasantness of odor is represented in the orbitofrontal cortex. In satiety experiments, Critchley and Rolls (1996c) showed that the responses of some olfactory neurons to a food odor are decreased during feeding to satiety with a food (e.g., fruit juice, or cream) containing that odor. In particular, seven of nine olfactory neurons that were responsive to the odors of foods, such as blackcurrant juice, were found to decrease their responses to the odor of the satiating food. The decrease was typically at least partly specific to the odor of the food that had been eaten to satiety, potentially providing part of the basis for sensory-specific satiety. It was also found for eight of nine neurons that had selective responses to the sight of food that they demonstrated a sensory-specific reduction in their visual responses to foods following satiation. These findings show that the olfactory and visual representations of food, as well as the taste representation of food, in the primate orbitofrontal cortex are modulated by hunger. Usually a component related to sensory-specific satiety can be demonstrated.

\subsection{THE RESPONSES OF ORBITOFRONTAL CORTEX TASTE AND OLFACTORY NEURONS TO THE SIGHT, TEXTURE, AND TEMPERATURE OF FOOD}

The orbitofrontal cortex of primates is also important as an area of convergence for somatosensory inputs, related, for example, to the texture of food including fat in the mouth. We have shown, for example, that single neurons influenced by taste in this region can in some cases have their responses modulated by the texture of the food. This was shown in experiments in which the texture of food was manipulated by the addition of methyl cellulose or gelatine, or by puréeing a semisolid food (Rolls, 1998, 1999).

It has been shown that some of these neurons with texture-related responses encode parametrically the viscosity of food in the mouth (using a methyl cellulose series in the range $1-10,000 \mathrm{cP}$ ), and that others independently encode the particulate quality of food in the mouth, produced quantitatively, for example, by adding 20-100 $\mu \mathrm{m}$ microspheres to $1000 \mathrm{cP}$ methyl cellulose ("Gritty") (Rolls et al., 2003b). The two neurons shown as examples on Figure 8.2 illustrate some of these properties. Neuron bk244 had a graded increase of firing rate to viscosity in the range $10-1000 \mathrm{cP}$, had no taste responses, did respond to oils, and did not respond to capsaicin. Neuron bo34 also had a graded increase of firing rate to viscosity in the range 10-10,000 cP; did respond to some tastes (glucose, sweet; $\mathrm{HCl}$, sour; and quinine, bitter) but not to others ( $\mathrm{NaCl}$ and MSG), did not respond to oils, and did respond to capsaicin. These neurons illustrate that taste, viscosity, fatty oils, and capsaicin can 

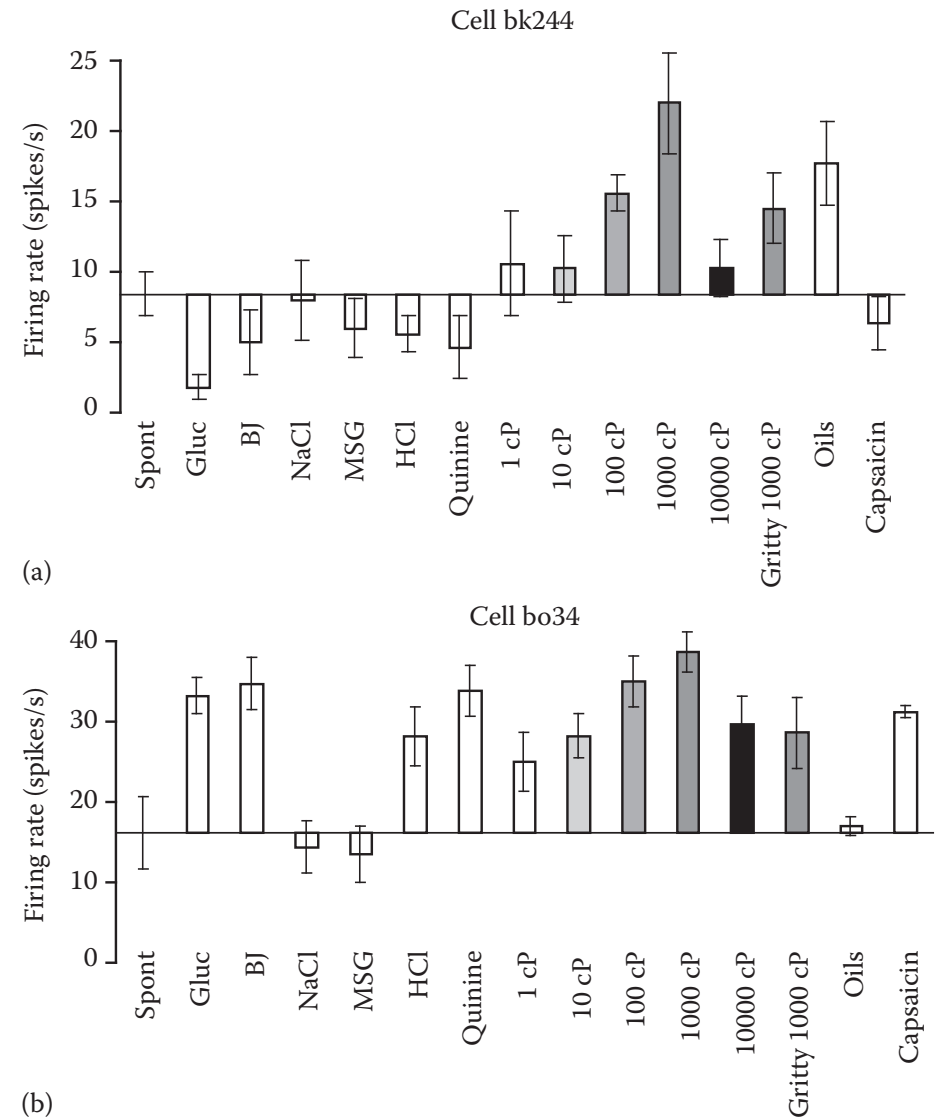

FIGURE 8.2 Oral somatosensory and taste inputs to orbitofrontal cortex neurons. (a) Firing rates (mean \pm sem) of viscosity-sensitive neuron bk 244 which did not have taste responses, in that it did not respond differentially to the different taste stimuli. The firing rates are shown to the viscosity series (CMC $1-10,000 \mathrm{cP}$, to the gritty stimulus (1000 cP CMC with Fillite microspheres), to the taste stimuli $1 \mathrm{M}$ glucose (Gluc), $0.1 \mathrm{M} \mathrm{NaCl}, 0.1 \mathrm{M} \mathrm{MSG}, 0.01 \mathrm{M} \mathrm{HCl}$ and $0.001 \mathrm{M}$ Quinine $\mathrm{HCl}$, and to fruit juice $(\mathrm{BJ})$. Spont = spontaneous firing rate. (b) Firing rates (mean \pm sem) of viscosity-sensitive neuron bo34 which had no response to the oils (mineral oil, vegetable oil, safflower oil, and coconut oil, which have viscosities that are all close to $50 \mathrm{cP}$ ). The neuron did not respond to the gritty stimulus in a way that was unexpected given the viscosity of the stimulus, was taste tuned, and did respond to capsaicin. (After Rolls, E.T. et al., J. Neurophysiol., 90, 3711, 2003. With permission.)

be coded for independently by a population of neurons of which these are examples. The oils used in this study included mineral oil, silicone oil, vegetable oil, coconut oil, and safflower oil (see Table 8.1) (Rolls et al., 2003b).

In addition, recent findings (Kadohisa et al., 2004) have revealed that some neurons in the orbitofrontal cortex reflect the temperature of substances in the mouth, and that this temperature information is represented independently of other sensory inputs by some neurons, and in combination with taste or texture by other neurons. 
TABLE 8.1

\section{Stimuli}

\begin{tabular}{|c|c|c|c|c|c|}
\hline Stimulus & Abbreviation & Concentration & MW & $\begin{array}{c}\text { App. } \\
\text { Viscosity (cP) }\end{array}$ & Chemical Group \\
\hline Glucose & G & $1 \mathrm{M}$ & 180 & 1 & $\begin{array}{l}\text { Monosaccharide } \\
\text { aldohexose }\end{array}$ \\
\hline $\begin{array}{l}\text { Black currant } \\
\text { juice }\end{array}$ & $\mathrm{BJ}$ & $20 \%$ & & 1 & Mixture \\
\hline $\begin{array}{l}\text { Monosodium } \\
\text { glutamate }\end{array}$ & M & $0.1 \mathrm{M}$ & 187 & 1 & Amino acid salt \\
\hline $\mathrm{NaCl}$ & $\mathrm{N}$ & $0.1 \mathrm{M}$ & 58 & 1 & Inorganic salt \\
\hline $\mathrm{HCl}$ & $\mathrm{H}$ & $0.01 \mathrm{M}$ & 36 & 1 & Inorganic acid \\
\hline Quinine $\mathrm{HCl}$ & Q & $0.001 \mathrm{M}$ & 387 & 1 & Alkaloid \\
\hline Water & $\mathrm{V} 1$ or $1 \mathrm{cP}$ & $5 \mathrm{mM} \mathrm{NaCl}$ & & 1 & \\
\hline $\mathrm{CMC}^{\mathrm{a}}$ & $\mathrm{V} 10$ or $10 \mathrm{cP}$ & $0.2 \mathrm{~g}+11 \mathrm{~V} 1$ & 70000 & 10 & Polysaccharide \\
\hline $\mathrm{CMC}$ & $\begin{array}{l}\text { V100 or } \\
100 \mathrm{cP}\end{array}$ & $4.0 \mathrm{~g}+11 \mathrm{~V} 1$ & 70000 & 100 & Polysaccharide \\
\hline $\mathrm{CMC}$ & $\begin{array}{c}\text { V1000 or } \\
1000 \mathrm{cP}\end{array}$ & $11.0 \mathrm{~g}+11 \mathrm{~V} 1$ & 70000 & 1000 & Polysaccharide \\
\hline $\mathrm{CMC}$ & $\begin{array}{c}\mathrm{V} 10,000 \text { or } \\
10,000 \mathrm{cP}\end{array}$ & $24.0 \mathrm{~g}+11 \mathrm{~V} 1$ & 70000 & 10,000 & Polysaccharide \\
\hline Mineral oil & MO & $100 \%$ & & 25 & $\begin{array}{l}\text { Hydrocarbon } \\
\text { mixture }\end{array}$ \\
\hline Silicone oil & $\mathrm{SiO}$ or $\mathrm{SilO}$ & $100 \%$ & & 100 or 280 & $\begin{array}{l}\text { Silicon-oxygen } \\
\text { polymer }\end{array}$ \\
\hline Vegetable oil & VOo or VOf & $100 \%$ & & 55 & Fat \\
\hline Coconut oil & $\mathrm{CO}$ & $100 \%$ & & 40 & Fat \\
\hline Safflower oil & $\mathrm{SaO}$ or $\mathrm{SafO}$ & $100 \%$ & & 50 & Fat \\
\hline Single cream & $\mathrm{SC}$ & $100 \%$ & & 12 & Emulsion \\
\hline $\begin{array}{l}\text { Lauric acid } \\
\text { C12:0 }\end{array}$ & $\mathrm{LaA}$ & $100 \mu \mathrm{M}$ & & 1 & FFA \\
\hline $\begin{array}{l}\text { Linoleic acid } \\
\text { C18:2 }\end{array}$ & $\mathrm{LiA}$ & $100 \mu \mathrm{M}$ & & 1 & FFA \\
\hline
\end{tabular}

\subsection{THE MOUTHFEEL OF FAT: ORBITOFRONTAL CORTEX, PRIMARY TASTE CORTEX, AND AMYGDALA}

Texture in the mouth is an important indicator of whether "fat" is present in a food, which is important not only as a high-value energy source, but also as a potential source of essential fatty acids. In the orbitofrontal cortex, Rolls et al. (1999) have found a population of neurons that responds to the texture of fat in the mouth. Figure 8.3 shows an example of one of these neurons. The neuron increased its firing rate to cream (double and single cream, with the fat proportions shown), and responded 


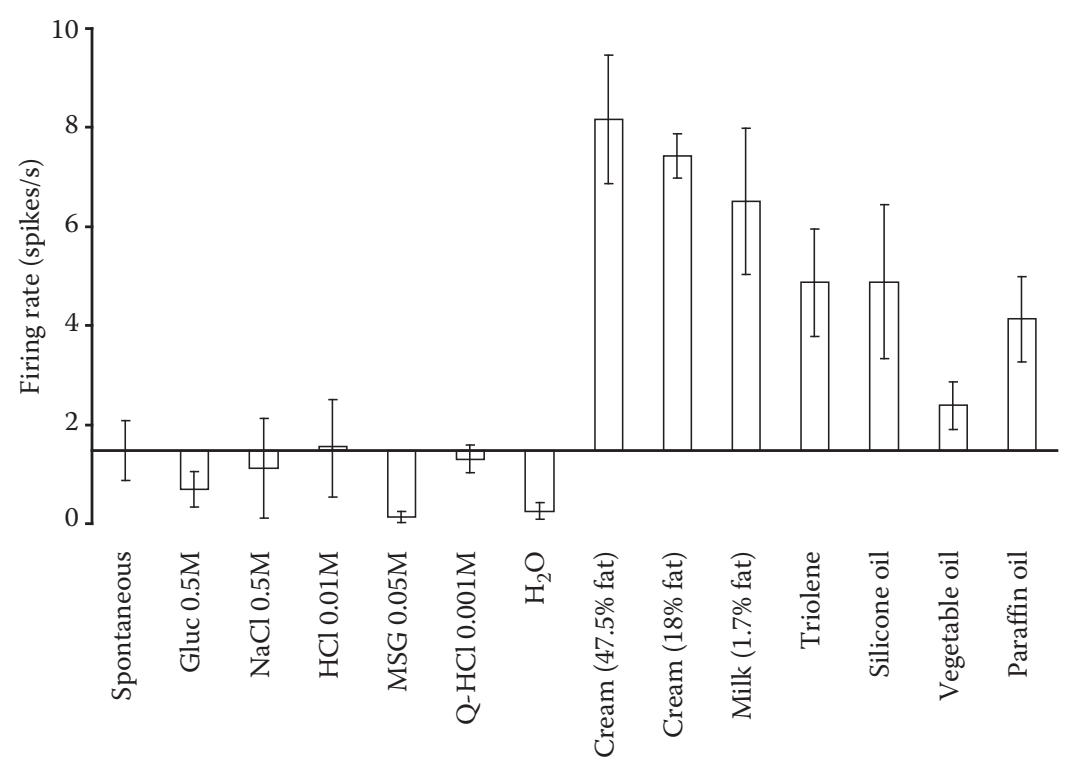

FIGURE 8.3 A neuron in the primate orbitofrontal cortex responding to the texture of fat in the mouth. The neuron increased its firing rate to cream (double and single cream, with the fat proportions shown), and responded to texture rather than the chemical structure of the fat in that it also responded to $0.5 \mathrm{~mL}$ of silicone oil $\left.\left(\mathrm{Si}_{(}\left(\mathrm{CH}_{3}\right)_{2} \mathrm{O}\right)_{n}\right)$ or paraffin oil (hydrocarbon). The neuron did not have a taste input. Gluc, glucose; $\mathrm{NaCl}$, salt; $\mathrm{HCl}$, sour; $\mathrm{Q}-\mathrm{HCl}$, quinine, bitter. The spontaneous firing rate of the cell is also shown. (After Rolls, E.T. et al., J. Neurosci., 19, 1532, 1999. With permission.)

to texture rather than the chemical structure of the fat in that it also responded to $0.5 \mathrm{~mL}$ of silicone oil $\left(\mathrm{Si}\left(\mathrm{CH}_{3}\right)_{2} \mathrm{O}\right)_{n}$ ) or paraffin oil (hydrocarbon). The neuron did not have a taste input. The firing rate responses are shown against the baseline spontaneous firing rate of the neuron.

Figure 8.4 shows an example of a fat-responsive neuron in the orbitofrontal cortex from the study of Verhagen et al. (2003a) where the evoked neuronal activity to the indicated stimuli is plotted as a function of viscosity. The cell showed strong and similar responses to all the oils tested, but did not respond to any of the carboxymethyl-cellulose (CMC) viscosity series below $10,000 \mathrm{cP}$, and to none of the CMC viscosity series with viscosities in the range of the oils. (The stimuli used, and their abbreviations, are in Table 8.1.) The neuronal responses were significantly different between the oils and the spontaneous firing rate and V10-V100 (both $p<.001$ ). Further, in contrast to the robust excitatory responses to safflower oil ( $45 \pm$ spikes/s) and coconut oil (50 \pm spikes/s), which are rich in LiA and lauric acid (LaA) bound into triglycerides, the responses to $\mathrm{LiA}$ and $\mathrm{LaA}$ were slightly below spontaneous rate, providing evidence that the neurons did not respond to fats based on gustatory sensitivity to the fatty acids. Figure 8.5 shows another example of a fat-sensitive neuron in the orbitofrontal cortex.

A different type of neuron is now described, to make it clear how selective the type of neuron shown in Figures 8.4 and 8.5 are for fat texture. In this comparison 


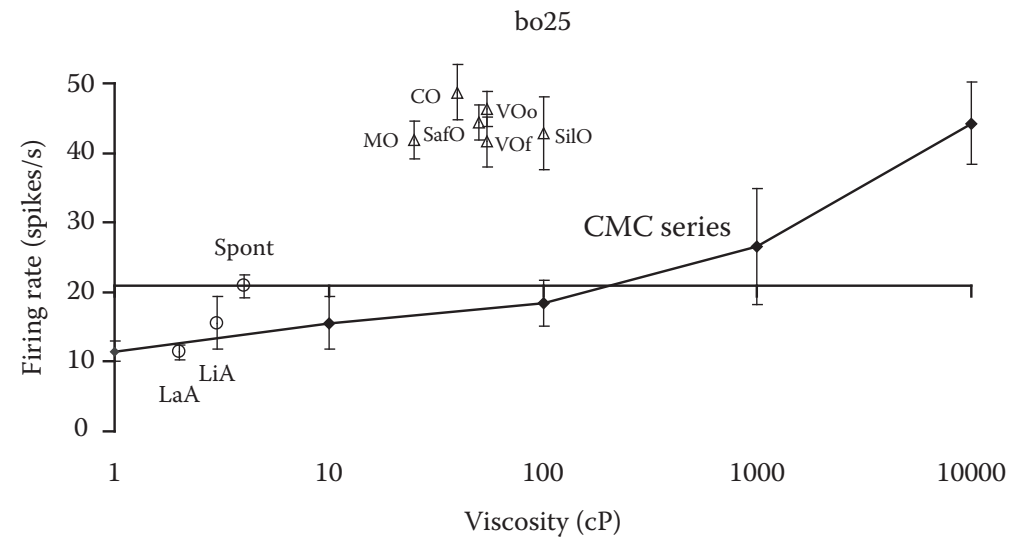

FIGURE 8.4 Evoked activity graphed against apparent stimulus viscosity for fat-responsive neuron bo25. The line indicates the responses to the CMC viscosity series. The mean and the standard error of the mean responses calculated in a $1 \mathrm{~s}$ period over four to six trials are shown here and elsewhere unless otherwise indicated. The oils evoked significantly higher activity than either the spontaneous activity or CMC at corresponding apparent viscosities. The oils were vegetable oil (VOo, VOf), safflower oil (SO), coconut oil (CO), silicone oil (SilO), and mineral oil (MO). Linoleic acid (Lin) and lauric acid (Lau) were also tested. Details of the stimuli are in Table 8.1. The information that reaches this type of neuron is independent of a viscosity-sensing channel, in that the neuron did not respond to the methyl cellulose (CMC) viscosity series. (After Verhagen, J.V. et al., J. Neurophysiol., 90, 1514, 2003a. With permission.)

Fat responsive neurons respond independently of viscosity e.g. bk265

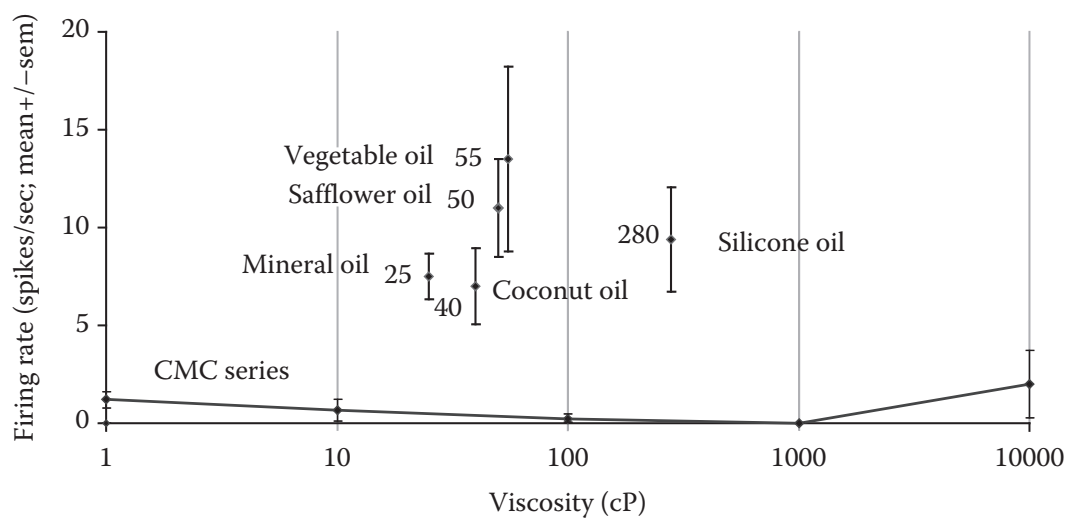

FIGURE 8.5 A neuron in the primate orbitofrontal cortex responding to the texture of fat in the mouth independently of viscosity. The cell (bk265) increased its firing rate to a range of fats and oils (the viscosity of which is shown in $\mathrm{cP}$ ). The information that reaches this type of neuron is independent of a viscosity-sensing channel, in that the neuron did not respond to the methyl cellulose (CMC) viscosity series. The neuron responded to the texture rather than the

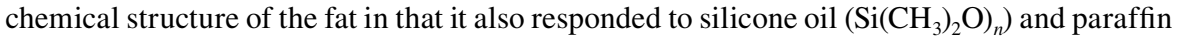
(mineral) oil (hydrocarbon). Some of these neurons have taste inputs. For abbreviations see Table 8.1. (After Verhagen, J.V., Rolls, E.T., and Kadohisa, M., J. Neurophysiol., 90, 1514, 2003a. With permission.) 


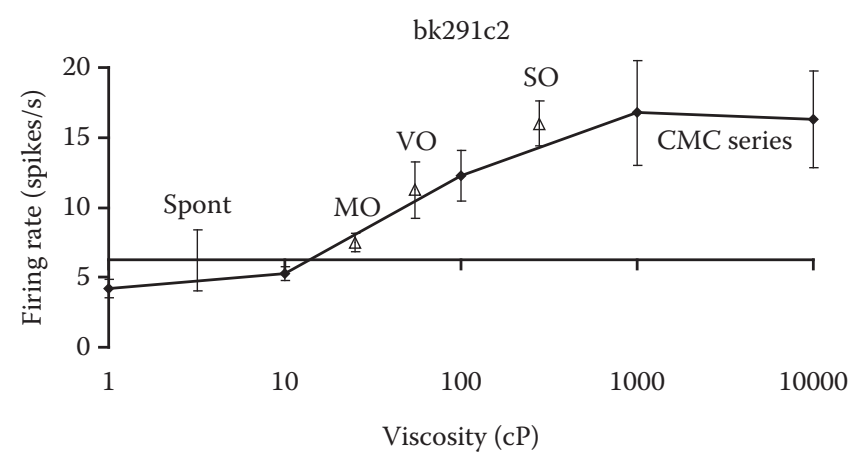

FIGURE 8.6 Evoked activity graphed against apparent stimulus viscosity for viscositysensitive neuron bk291c2. The line indicates the responses to the CMC series. The oil-evoked activity follows that evoked by the CMC viscosity stimuli at corresponding apparent viscosities. For abbreviations see Table 8.1. (After Verhagen, J.V. et al., J. Neurophysiol., 90, 1514, 2003a. With permission.)

type of neuron, the responses to oils were apparently determined by the viscosity of the oils, and the neurons were effectively viscosity-sensitive rather than fat-sensitive. For example, the neuron illustrated in Figure 8.6 showed an increasing neuronal response as the viscosity of the CMC series increased from V10-V1000; and the responses to mineral, vegetable, and silicone oil, plotted at their viscosities, follow this viscosity-sensitivity curve closely.

We also observed neurons that did respond to the CMC viscosity series but not to the oils (Verhagen et al., 2003a). This type of neuronal response, which also illustrates how neurons can be tuned to a range of viscosities, is exemplified by the neuron shown in Figure 8.7. The neuronal responses show an upward trend with increasing viscosity (V1-V1000), and a reduction at V10,000. However, none of the oils evoked significant activity. Thus the responses of this neuron show another way in which orbitofrontal cortex neurons can discriminate between fat texture and viscosity, by in this case responding to information conveyed through a viscosity information channel but not through a fat-sensitive information channel. Part of the interest of this type of neuron is that although the oils had viscosities that were in the range 25-100 cP (see Table 8.1), the neuron did not respond to this level of viscosity when it was expressed through the presence of an oil. This provides evidence that oils must therefore have other textural properties (reflected for example in their slickness) that prevent this type of neuron from responding. This neuron had firing rates to LiA and LaA (4, 3 spikes/s, respectively) that were predictable by their viscosity, as shown in Figure 8.7.

In this study, $5.4 \%$ of the orbitofrontal cortex neurons responded to fat, viscosity and/or taste (Verhagen et al., 2003a). Of the 14 neurons with responses to fat in the mouth where the response to fat was independent of viscosity (i.e., could not be predicted from viscosity) (1.6\% of all screened neurons), 9 responded to both taste and to fat, 4 to taste and to viscosity, and 1 did not respond to taste or to viscosity. Thirteen of the 18 neurons responsive to viscosity also responded to taste, 4 of those 
bo13

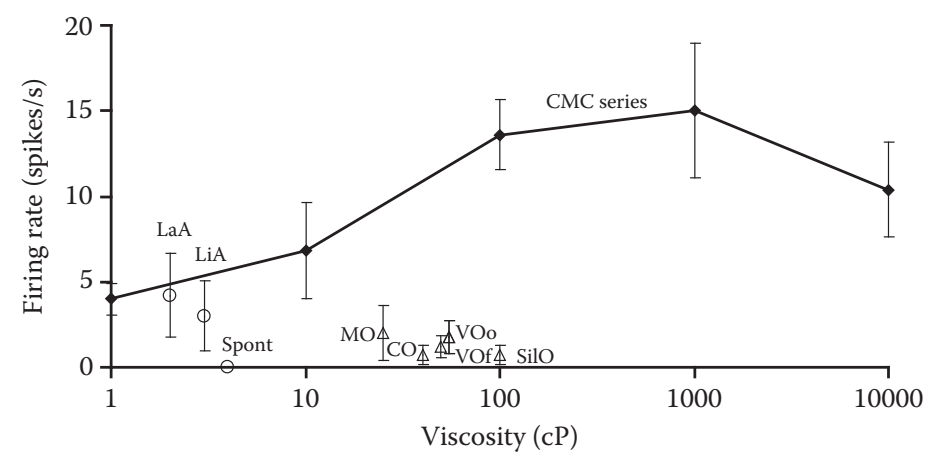

FIGURE 8.7 Evoked activity graphed against apparent stimulus viscosity for neuron bo13. The line indicates the responses to the CMC series. This neuron did respond to viscosity (of the CMC series) but no activity was evoked by the oils. For abbreviations see Table 8.1. (After Verhagen, J.V. et al., J. Neurophysiol., 90, 1514, 2003a. With permission.)

also to fat where the response to the fat could be predicted from the viscosity, and 5 responded to only viscosity. In addition, the number of neurons that was tuned to the CMC viscosity series and which did not respond to fat in the way that would be predicted by the CMC viscosity tuning (see example in Figure 8.7) was 4 of the 50 neurons analyzed.

The results of these studies on orbitofrontal cortex neurons (Rolls et al., 1999; Verhagen et al., 2003a) show that fat-sensitive neurons respond not only to fats such as vegetable oil and other fatty oils in the mouth, and to substances rich in fat such as cream and chocolate, but also to chemically different substances which have a similar slick or oily texture such as mineral oil (pure hydrocarbon), and silicone oil $\left.\left(\mathrm{Si}\left(\mathrm{CH}_{3}\right)_{2} \mathrm{O}\right)_{n}\right)$. This evidence thus indicates that the mechanisms that sense fat and to which these neurons respond are sensing a physical rather than a chemical property of the stimuli. The results also provide evidence that the responses of fat-sensitive neurons are not based on a texture information channel that is tuned to viscosity. In particular, although some neurons in the orbitofrontal cortex are tuned to viscosity (see examples in Figures 8.6 and 8.7), many (10/14) of the fat-sensitive neurons did not respond to the viscosity series of stimuli (see examples in Figures 8.4 and 8.5); or had responses to the fats and some of the $\mathrm{CMC}$ viscosity series, where the response to fat could not be accounted for by viscosity (4/14); and 4 neurons were responsive to viscosity but did not respond to fat (see example in Figure 8.7). The latter type of neuron (Figure 8.7) is rather interesting, for the implication is that although there is a viscosity-sensing channel that responds to stimuli including fats based on their viscosity (Figure 8.6), there is also a mechanism for representing viscosity when it is not produced by a fatty oily stimulus, as in Figure 8.7.

Important conclusions then about the representation of oral texture in the brain (and illustrated by the types of neuron shown in Figures 8.4 through 8.7 ) are (1) There is an information channel that represents fat independently of viscosity. (2) There is an information channel that represents viscosity and also responds to fat based on the 
viscosity of the fat. This channel thus responds to viscosity independent of whether the eliciting stimulus is a nonfat or a fat. (3) There is an information channel that encodes viscosity provided that it is not associated with an oily substance such as a fat. The third type of channel could reflect a separate sensing mechanism in the mouth; or it could reflect competitive and expansion recoding processes (Rolls and Deco, 2002; Rolls, 2008c) produced in the cortex by inputs reflecting, for example, fat sensitivity without viscosity in a first channel, and viscosity with fat sensitivity in another channel.

Gustatory mechanisms have been revealed in rat oral taste cells that may mediate a possible fat taste: the slow modulation of K-channels by polyunsaturated FFA such as LiA (Gilbertson et al., 1997; Gilbertson, 1998). However, salivary lipase which could release fatty acid from fat in rats to activate such a mechanism, is hardly present in humans (Gilbertson et al., 1997; Gilbertson, 1998), so that this mechanism may not be important in humans. Further evidence that this chemical sensing mechanism may not be important in primates including humans is that the time course of the activation of the K-channel mechanism is very slow (Gilbertson et al., 1997; Gilbertson, 1998), and does not match the rapidly developing subjective sensation of fat in the mouth. However, to test this possibility, responses by the population of orbitofrontal cortex neurons to the FFA, LiA, and LaA were measured, and for most neurons responses were not found, that is for most neurons the activity evoked by these stimuli was indistinguishable to that evoked by water (Verhagen et al., 2003a). In particular, of 37 neurons tested with $\mathrm{LaA}$ and $\mathrm{LiA}, 34$ had no significant responses compared to water. Of the three neurons that had statistically significant responses in this comparison, all three consisted of a smaller response than was obtained to water, and in two cases the statistical significance was marginal, i.e., $p \approx .05$. To assess whether the firing rates obtained to $\mathrm{LaA}$ and $\mathrm{LiA}$ could predict the responses of the neurons to coconut oil (high in lauric conjugated to glycerol) and to safflower (high in LiA conjugated to glycerol), linear regression analysis was performed across the sample of 14 fat-sensitive neurons in the orbitofrontal cortex (Verhagen et al., 2003a). There was no significant correlation between the responses to the fatty acids and these two fat stimuli. (For LaA, $r=.45, p=.20$; for $\mathrm{LiA}, r=.61, p=.06$.) Thus, the responses to fats by this population of neurons cannot be accounted for by sensitivity to LaA and LiA. By contrast, the responses to fats could be predicted by their response to the texture of silicone oil. (For silicone oil vs. coconut oil $r=.99, p<.001$; while for silicone oil vs. safflower oil $r=.99, p<.001$.) Together, these points of evidence (Verhagen et al., 2003a) suggest that fat in the mouth can be sensed in primates at least independently of any oral gustatory mechanism for FFA (a mechanism suggested by Gilbertson (1998) in rodents). These data suggest that different sensing mechanisms and percepts are evoked by FFA as compared to fatty oils. Perceptual responses to FFA, if large enough not to also taste sour (Forss, 1972), depend at least partly on the trigeminal nociceptive pathway and may be associated with the percept of oral irritation. The oils, whether triglyceride-based or not, are sensed by a somatosensory-textural pathway and may be associated with the mouthfeel of fat/slickness.

Some of the fat-related neurons do though receive convergent inputs from the chemical senses, in that in addition to taste inputs, some of these neurons respond to the odor associated with a fat, such as the odor of cream (Rolls et al., 1999). Feeding 
to satiety with fat (e.g., cream) decreases the responses of these orbitofrontal cortex neurons to zero on the food eaten to satiety [including its odor (Critchley and Rolls, 1996c)], but if the neuron receives a taste input from, for example, glucose taste, that is not decreased by feeding to satiety with cream (Rolls et al., 1999). Thus there is a representation of the macronutrient fat in this brain area, and the activation produced by fat is reduced by eating fat to satiety. It is thus the reward, affective, or hedonic value of fat that is represented in the orbitofrontal cortex.

The common perceptual quality among the oils is the slick/fatty mouthfeel. The function of the fat texture-sensitive neurons (Rolls et al., 1999; Verhagen et al., 2003a) may be to allow recognition of fatty substances in the mouth, based on texture information received through the somatosensory system. Consistent with this, Mela (1988) reported that humans rate the fat content of dairy products based on their textural properties. We note that the types of neuron described here, responding to fat independently of viscosity, to viscosity whether it is produced by nonfat or by fat, and to viscosity when it is not being produced by a fatty/oily texture, provide an excellent representation of many textural properties of food, including creaminess, for which ratings provided by humans depend on a variety of textural properties (Bourne, 2002). Further breadth to the representation is provided by the taste and olfactory inputs to some fat-sensitive neurons (Critchley and Rolls, 1996c; Rolls et al., 1999; Verhagen et al., 2003a). This is consistent with the hypothesis that a food's flavor (and appearance) is represented in the orbitofrontal cortex by integration of somatosensory, gustatory, temperature, olfactory, visual, and cognitive information in such multimodal neurons (Rolls and Baylis, 1994; Critchley and Rolls, 1996a,c; Rolls et al., 1996a, 2008b; Kadohisa et al., 2004; Guest et al., 2007; Rolls, 2007; Grabenhorst and Rolls, 2008; Grabenhorst et al., 2008).

Fat texture, oral viscosity, and temperature, for some neurons in combination with taste, are represented in the macaque primary taste cortex in the rostral insula and adjoining frontal operculum (Verhagen et al., 2004). This could reflect convergence of taste and texture inputs in the insular cortex, or the convergence could be present already at earlier stages of taste processing. It is known that some neurons in the taste thalamus (nucleus VPMpc) have thermal responsiveness in monkeys (Pritchard et al., 1989) and rats (Verhagen et al., 2003b). In the periphery, it is known that chorda tympani fibers in the monkey (Sato et al., 1975) and hamster (Ogawa et al., 1968) show significant correlations between the responses to $\mathrm{HCl}$ and those to cooling $\left(20^{\circ} \mathrm{C}\right.$ ), and between the responses to sucrose and warming (to $40^{\circ} \mathrm{C}$ ). Some lingual nerve fibers in monkeys were activated by cooling to $15^{\circ} \mathrm{C}$ but not by taste (Danilova and Hellekant, 2002). There may be no studies in the periphery of the effects of food-relevant oral stimuli such as viscosity and fat texture. It is also possible that oral somatosensory information reaches the anterior insular/frontal opercular primary taste cortex via cortico-cortical connections, perhaps from areas $3 \mathrm{~b}$ which contain oral somatosensory representations of, for example, touch of the tongue, teeth, and palate (Manger et al., 1996; Jain et al., 2001) and which might send afferents to the anterior insular/frontal opercular primary taste cortex (Mufson and Mesulam, 1982; Friedman et al., 1986).

Given that an important input to the orbitofrontal cortex is from the primary taste cortex (Baylis et al., 1995), the responses of orbitofrontal cortex neurons to fat 
texture, and also oral viscosity, temperature, and taste, are likely to be produced at least in a large part via the primary taste cortex.

These oral sensory properties of food, including viscosity and fat texture, and also the sight and smell of food, are also represented in the primate amygdala (Rolls, 2000c; Rolls and Scott, 2003; Kadohisa et al., 2005a,b), which also receives inputs from the primary taste cortex. Interestingly, the responses of these amygdala neurons do not correlate well with the preferences of the macaques for the oral stimuli (Kadohisa et al., 2005a), and feeding to satiety does not produce the large reduction in the responses of amygdala neurons to food (Rolls, 2000c; Rolls and Scott, 2003) that is typical of orbitofrontal cortex neurons.

\subsection{ACTIVATION OF THE HUMAN BRAIN BY ORAL SIGNALS, INCLUDING FAT TEXTURE}

\subsubsection{TASTE}

In humans it has been shown in neuroimaging studies using functional Magnetic Resonance Imaging (fMRI) that taste activates an area of the anterior insular/ frontal opercular cortex, which is probably the primary taste cortex, and part of the orbitofrontal cortex, which is probably the secondary taste cortex (Francis et al., 1999; Small et al., 1999; O'Doherty et al., 2001; de Araujo et al., 2003b). It has been shown that within individual subjects separate areas of the orbitofrontal cortex are activated by sweet (pleasant) and by salt (unpleasant) tastes (O'Doherty et al., 2001).

Francis et al. (1999) also found activation of the human amygdala by the taste of glucose. Extending this study, O'Doherty et al. (2001) showed that the human amygdala was as much activated by the affectively pleasant taste of glucose as by the affectively negative taste of $\mathrm{NaCl}$, and thus provided evidence that the human amygdala is not especially involved in processing aversive as compared to rewarding stimuli. Zald et al. (1998) had shown earlier that the amygdala, as well as the orbitofrontal cortex, respond to aversive (saline) taste stimuli. The study above (O'Doherty et al., 2001), however, shows that there is nothing special about aversive taste stimuli in relation to the brain areas activated, for pleasant stimuli also activate the amygdala and orbitofrontal cortex.

Another study has shown that umami taste stimuli, of which an exemplar is MSG and which capture what is described as the taste of protein, activate similar cortical regions of the human taste system to those activated by a prototypical taste stimulus, glucose (de Araujo et al., 2003a). A part of the rostral anterior cingulate cortex (ACC) was also activated. When the nucleotide $0.005 \mathrm{M}$ inosine $5^{\prime}$-monophosphate (IMP) was added to MSG (0.05 M), the BOLD (blood oxygenation-level dependent) signal in an anterior part of the orbitofrontal cortex showed supralinear additivity, and this may reflect the subjective enhancement of umami taste that has been described when IMP is added to MSG. Overall, these results illustrate that the responses of the brain can reflect inputs produced by particular combinations of sensory stimuli with supralinear activations, and that the combination of sensory stimuli may be especially represented in particular brain regions. 


\subsubsection{ODOR}

In humans, in addition to activation of the pyriform (olfactory) cortex (Zald and Pardo, 1997; Sobel et al., 2000; Poellinger et al., 2001), there is strong and consistent activation of the orbitofrontal cortex by olfactory stimuli (Zatorre et al., 1992; Francis et al., 1999). In an investigation of where the pleasantness of olfactory stimuli might be represented in humans, O'Doherty et al. (2000) showed that the activation of an area of the orbitofrontal cortex to banana odor was decreased (relative to a control vanilla odor) after bananas were eaten to satiety. Thus activity in a part of the human orbitofrontal cortex olfactory area is related to sensory-specific satiety, and this is one brain region where the pleasantness of odor is represented.

An important issue is whether there are separate regions of the brain discriminable with fMRI that represent pleasant and unpleasant odors. To investigate this, we measured the brain activations produced by three pleasant and three unpleasant odors. The pleasant odors chosen were linalyl acetate (floral, sweet), geranyl acetate (floral), and alpha-ionone (woody, slightly food-related). The unpleasant odors chosen were hexanoic acid, octanol, and isovaleric acid. We found that they activated dissociable parts of the human brain (Rolls et al., 2003a). Pleasant but not unpleasant odors were found to activate a medial region of the rostral orbitofrontal cortex. Further, there was a correlation between the subjective pleasantness ratings of the six odors given during the investigation with activation of a medial region of the rostral orbitofrontal cortex. In contrast, a correlation between the subjective unpleasantness ratings of the six odors was found in regions of the left and more lateral orbitofrontal cortex. Activation was also found in the ACC, with a middle part of the anterior cingulate activated by both pleasant and unpleasant odors, and a more anterior part of the ACC showing a correlation with the subjective pleasantness ratings of the odors (Rolls et al., 2003a). These results provide evidence that there is a hedonic map of the sense of smell in brain regions such as the orbitofrontal cortex and cingulate cortex.

\subsubsection{Olfactory-Taste Convergence to Represent Flavor, and the INfLuence of SATIETy}

To investigate where in the human brain interactions between taste and odor stimuli may be realized to implement flavor, we performed an event-related fMRI study with sucrose and MSG taste, and strawberry and methional (chicken) odors, delivered unimodally or in different combinations (de Araujo et al., 2003c). The brain regions that were activated by both taste and smell included parts of the caudal orbitofrontal cortex, amygdala, insular cortex and adjoining areas, and ACC. It was shown that a small part of the anterior (putatively agranular) insula responds to unimodal taste and to unimodal olfactory stimuli; and that a part of the anterior frontal operculum is a unimodal taste area (putatively primary taste cortex) not activated by olfactory stimuli. Activations to combined olfactory and taste stimuli where there was little or no activation to either alone (providing positive evidence for interactions between the olfactory and taste inputs) were found in a lateral anterior part of the orbitofrontal cortex. Correlations with consonance ratings for the smell and taste combinations, and for their pleasantness, were found in a medial anterior part of the orbitofrontal 
cortex. Similarly, Small et al. (2004) also found supra-additive interactions between congruent taste and smell stimuli in areas including the caudal orbitofrontal cortex, and ACC (see also Small and Prescott, 2005). These results provide evidence on the neural substrate for the convergence of taste and olfactory stimuli to produce flavor in humans, and where the pleasantness of flavor is represented in the human brain.

McCabe and Rolls (2007) have shown that the convergence of taste and olfactory information appears to be important for the delicious flavor of umami. They showed that when glutamate is given in combination with a consonant, savory, odor (vegetable), the resulting flavor can be much more pleasant than the glutamate taste or vegetable odor alone. Moreover, they found using functional brain imaging with fMRI that the glutamate and savory odor combination produced much greater activation of the pregenual cingulate cortex and medial orbitofrontal cortex than the sum of the activations by the taste and olfactory components presented separately. Further, activations in these brain regions were correlated with the pleasantness, consonance of the taste and olfactory components, and the fullness of the flavor, of the stimuli. Similar nonlinear effects were not found for sodium chloride and vegetable odor. Rolls and McCabe thus proposed that glutamate acts by the nonlinear effects it can produce when combined with a consonant odor. They further proposed the concept that umami can be thought of as a rich and delicious flavor that is produced by a combination of glutamate taste and a consonant savory odor. Glutamate is thus a flavor enhancer because of the way that it can combine nonlinearly with consonant odors.

\subsubsection{Oral Viscosity and Fat Texture}

To investigate the representation of oral texture including fat texture in the human brain, de Araujo and Rolls (2004) used event-related fMRI while stimuli of three viscosities $(1 \mathrm{cP}$ and $\mathrm{CMC} 50$, and $1000 \mathrm{cP}$ ), a fatty oil, or $1 \mathrm{M}$ sucrose used to localize taste areas, were delivered intra-orally in volumes of $0.75 \mathrm{~mL}$. The fat stimulus was vegetable oil (rapeseed oil consisting of $6.1 \mathrm{~g}$ of saturate fat, $54.4 \mathrm{~g}$ of mono-unsaturated fat, and $26.9 \mathrm{~g}$ of polyunsaturated fat per $100 \mathrm{~mL}$, Sainsbury's Supermarkets, U.K.) with a measured viscosity of $50 \mathrm{cP}$. This oil was chosen as it was the most odorless and tasteless of those that could be obtained. A tasteless solution [containing the main ionic components of saliva, $25 \mathrm{mM} \mathrm{KCl}+2.5 \mathrm{mM}$ $\mathrm{NaHCO}_{3}$ in distilled water (de Araujo et al., 2003b)] was used as a control which was subtracted from the activations to the test stimuli.

First, we found activation of the anterior insular (putative primary) taste cortex of humans by oral viscosity stimuli (Figure 8.8 middle), in a region that was shown to be taste-related by its activations to oral sucrose. Indeed, the BOLD activation here was proportional to the $\log$ of the viscosity of the oral stimuli. Fat also activated this region (Figure 8.8 middle), though not in a way that was identified with the fMRI method as being qualitatively different from the activation produced by a viscosity stimulus made to the same viscosity value with CMC. We hypothesized therefore that the activation of this region in humans corresponds to the details revealed by single neuron recording in macaques, namely that some neurons in the primary taste cortex are activated by taste unimodally, some by viscosity unimodally, some by 

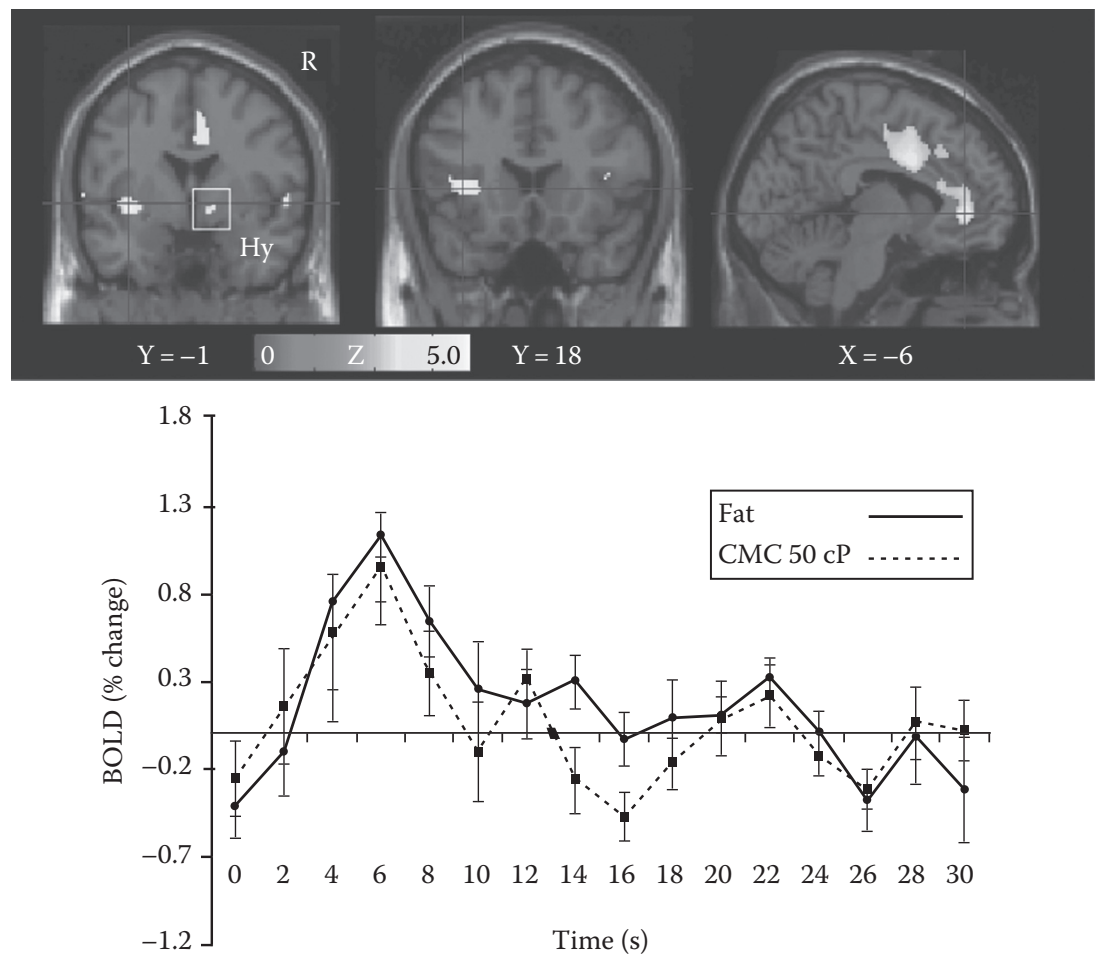

FIGURE 8.8 (See color insert following page xxx.) fMRI study of the responses to the oral delivery of fat as assessed by the comparison (fat-control). Activations were observed in the mid-insula and hypothalamus (Hy) (top row left), anterior insula (top row middle), and ACC (top row right). The average time-course data (across trials and subjects) from the midinsular cortex (from the voxels marked by the crosshairs in the top row left) are shown in the bottom row for the conditions Fat and CMC 50 cP. (After de Araujo I.E.T. and Rolls E.T., J. Neurosci., 24, 3086, 2004. With permission.)

both taste and viscosity, and some by fat texture (Verhagen et al., 2004). The fMRI findings on the human anterior insular cortex are consistent with the hypothesis that the same processing takes place in the human anterior insular cortex (de Araujo and Rolls, 2004).

Second, we found activation of a mid-insular region behind the primary taste cortex that was activated by viscosity and by fat but not by taste (Figure $8.8 \mathrm{left}$ ). This may be a purely somatosensory part of the insula that is a higher order somatosensory cortical area, the part of which is devoted to intra-oral somatosensory inputs. The somatosensory representation of the oral cavity is located in this part of the insula extending anteriorly to the orbitofrontal cortex (Manger et al., 1996; Jain et al., 2001). This mid-insular cortex may represent a range of somatosensory properties of the oral activity, for in a study of the effects of intra-oral water, we found that activation in the same mid-insular region was produced by water when thirsty 
but not after thirst was quenched. We interpreted this as a somatosensory effect related to relief of a dry mouth by water, in that this region was again not activated by taste stimuli (de Araujo et al., 2003b).

Third, we found activations produced by fat in the mouth in the orbitofrontal cortex, where some neurons in macaques specifically encode oral fat independently of viscosity (Rolls et al., 2003b; Verhagen et al., 2003a), in a region to which this projects, the pregenual cingulate cortex (Figure 8.8 right, at the location shown by the crosshairs), and also more dorsally in the ACC (Figure 8.8 right). The activation by fat in the pregenual cingulate cortex was especially interesting, in that the activation here to fat was independent of viscosity (produced by CMC) (see Figure 8.9). This pregenual cingulate region was also activated by sucrose taste, and is a strong candidate for a brain region activated by the hedonic properties of fat. This pregenual cingulate region has been shown to contain taste-responsive neurons (Rolls, 2008b). Further evidence linking this pregenual cingulate region to pleasant affective properties (Bush et al., 2000) of sensory stimuli is that the same region is activated by water when it tastes pleasant during thirst (de Araujo et al., 2003b), by pleasant but not unpleasant odors (Rolls et al., 2003a), and by pleasant but not by painful touch (Rolls et al., 2003c). Further, this pregenual cingulate region is also implicated in the control of autonomic function (Critchley et al., 2004). Further, the ACC can be activated by hedonically relevant stimuli, including chemosensory, and somatosensory stimuli (Zald et al., 1998; Small et al., 1999; Zatorre et al., 2000; Rolls, 2005, 2008a; McCabe and Rolls, 2007; Rolls and McCabe, 2007; Grabenhorst and Rolls, 2008; Grabenhorst et al., 2008; McCabe et al., 2008; Rolls and Grabenhorst, 2008; Rolls et al., 2008a,b).

The findings show that the details of the representation of fat and oral texture that has been uncovered by single neuron analyses in the macaque insula, orbitofrontal cortex, and connected areas is likely to also apply in humans in the corresponding areas in which activations to similar stimuli have been found (de Araujo and Rolls, 2004).

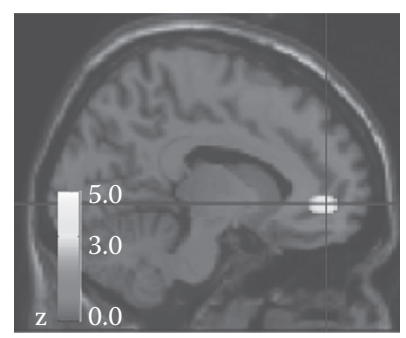

(a)

$$
X=-10
$$

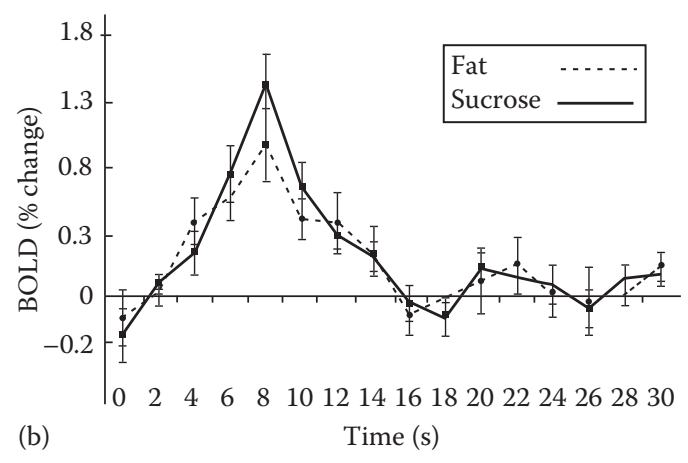

FIGURE 8.9 (See color insert following page xxx.) (a) Rostral ACC activation by fat-control and sucrose-control, as revealed by conjunction analysis. (b) The corresponding average time-course data (across trials and subjects) from the voxel marked by the crosshairs are shown. (After de Araujo I.E.T. and Rolls E.T., J. Neurosci., 24, 3086, 2004. With permission.) 


\subsubsection{The Pleasantness of the Flavor of Food}

To assess how satiety influences the brain activations to a whole food which produces taste, olfactory, and texture stimulation, we measured brain activation by whole foods before and after the food was eaten to satiety (de Araujo et al., 2003a). The aim was to show using a food that has olfactory, taste, and texture components the extent of the region that shows decreases when the food becomes less pleasant, in order to identify the different brain areas where the pleasantness of the odor, taste, and texture of food are represented. The foods eaten to satiety were either chocolate milk (which had a fat texture component), or tomato juice (which did not have a fat texture component). A decrease in activation by the food eaten to satiety relative to the other food was found in the orbitofrontal cortex (Kringelbach et al., 2003) but not in the primary taste cortex (see Figure 8.10). This study provided evidence that the pleasantness of the flavor of food, and sensory-specific satiety, are represented in the human orbitofrontal cortex.

Given that there are individual differences in the palatability of food, can these individual differences be related to the functioning of brain systems such as the

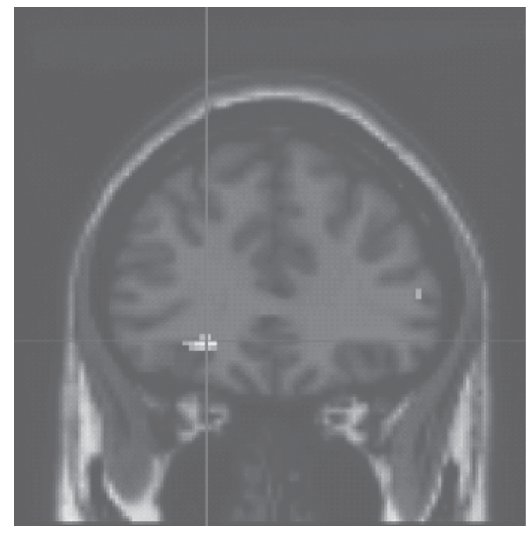

(a)

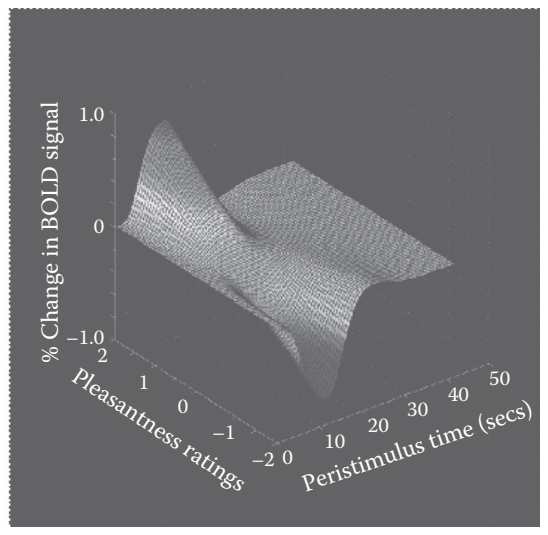

(b)

FIGURE 8.10 (See color insert following page xxx.) Areas of the human orbitofrontal cortex with activations correlating with pleasantness ratings for food in the mouth. (a) Coronal section through the region of the orbitofrontal cortex from the random effects group analysis showing the peak in the left orbitofrontal cortex (Talairach coordinates $x, y, z=-22,34,-8$, $Z$-score $=4.06$ ), in which the BOLD signal in the voxels shown in yellow was significantly correlated with the subjects' subjective pleasantness ratings of the foods throughout an experiment in which the subjects were hungry and found the food pleasant, and were then fed to satiety with the food, after which the pleasantness of the food decreased to neutral or slightly unpleasant. The design was a sensory-specific satiety design, and the pleasantness of the food not eaten in the meal, and the BOLD activation in the orbitofrontal cortex, were not altered by eating the other food to satiety. The two foods were tomato juice and chocolate milk. (b) Plot of the magnitude of the fitted hemodynamic response from a representative single subject against the subjective pleasantness ratings (on a scale from -2 to +2 ) and peristimulus time in seconds. (After Kringelbach, M.L. et al., Cereb. Cortex, 13, 1064, 2003. With permission.) 
orbitofrontal and pregenual cingulate cortex involved in the affective (hedonic) representations of food?

Some individuals, chocolate cravers, report that they crave chocolate more than noncravers, and this is associated with increased liking of chocolate, increased wanting of chocolate, and eating chocolate more frequently than noncravers (Rodriguez et al., 2007). In a test of whether these individual differences are reflected in the affective systems in the orbitofrontal cortex and pregenual cingulate cortex, Rolls and McCabe (2007) used fMRI to measure the response to the flavor of chocolate, to the sight of chocolate, and to their combination, in chocolate cravers vs. noncravers. It was shown that the sight of chocolate produced more activation in chocolate cravers than noncravers in the medial orbitofrontal cortex and ventral striatum. For cravers vs. noncravers, a combination of a picture of chocolate with chocolate in the mouth produced a greater effect than the sum of the components (i.e., supralinearity) in the medial orbitofrontal cortex and pregenual cingulate cortex. Furthermore, the pleasantness ratings of the chocolate and chocolate-related stimuli had higher positive correlations with the fMRI BOLD signals in the pregenual cingulate cortex and medial orbitofrontal cortex in the cravers than in the noncravers. Thus there were differences between cravers and noncravers in their responses to the sensory components of a craved food in the orbitofrontal cortex, pregenual cingulate cortex, and ventral striatum, and in some of these regions the differences are related to the subjective pleasantness of the craved foods. Differences in the insular taste cortex were not found. An implication is that individual differences in brain responses to very pleasant foods help to understand the mechanisms that drive the liking for specific foods by indicating that some (but not other brain systems such as the insular taste cortex) respond more to the rewarding aspects of some foods, and thus influence and indeed even predict the intake of those foods (which was much higher in chocolate cravers than noncravers) (Rolls and McCabe, 2007). Although texture is of course not the only contributor to the effects of chocolate, it is one important aspect of the sensory properties of chocolate.

\subsection{CONCLUSIONS}

Fat in the mouth is represented by its texture in the primary taste cortex in the insula, in the orbitofrontal cortex, in the amygdala, and in the ACC. Fat texture is represented by neurons independently of viscosity: some neurons respond to fat independently of viscosity, and other neurons encode viscosity. The neurons that respond to fat also respond to silicone oil and paraffin oil, indicating that the sensing is not chemospecific, but is instead based on texture. This fat sensing is not related to FFA, in that these neurons typically do not respond to FFA such as LiA. Moreover, a few neurons with responses to FFA typically do not respond to fat in the mouth. The fat texture representations by neurons may be combined with taste and/or oral temperature responses, and in the orbitofrontal cortex with olfactory responses. Different neurons respond to different combinations, providing a rich representation of the sensory properties of food. In the orbitofrontal cortex, feeding to satiety with one food decreases the responses of these neurons to that food, but not to other foods, showing that sensory-specific satiety and appetite modulation are represented in the 
orbitofrontal cortex. In humans, individual differences in activations in areas such as the orbitofrontal cortex and pregenual cingulate cortex to a complex food such as chocolate are related to the affective value of the foods, and how much is eaten. In summary, one way in which fat in the mouth is represented in the brain is by its texture, and an indication of what must be transduced has been provided by these neuroscience studies.

\section{ACKNOWLEDGMENTS}

This research was supported by the Medical Research Council.

\section{REFERENCES}

Baylis LL and Rolls ET, 1991. Responses of neurons in the primate taste cortex to glutamate. Physiology and Behavior 49:973-979.

Baylis LL, Rolls ET, and Baylis GC, 1995. Afferent connections of the orbitofrontal cortex taste area of the primate. Neuroscience 64:801-812.

Bourne MC, 2002. Food Texture and Viscosity: Concept and Measurement, 2nd edn. London: Academic Press.

Bush G, Luu P, and Posner MI, 2000. Cognitive and emotional influences in anterior cingulate cortex. Trends in Cognitive Sciences 4:215-222.

Cabanac M, 1971. Physiological role of pleasure. Science 173:1103-1107.

Critchley HD and Rolls ET, 1996a. Olfactory neuronal responses in the primate orbitofrontal cortex: Analysis in an olfactory discrimination task. Journal of Neurophysiology 75:1659-1672.

Critchley HD and Rolls ET, 1996b. Responses of primate taste cortex neurons to the astringent tastant tannic acid. Chemical Senses 21:135-145.

Critchley HD and Rolls ET, 1996c. Hunger and satiety modify the responses of olfactory and visual neurons in the primate orbitofrontal cortex. Journal of Neurophysiology 75:1673-1686.

Critchley HD, Wiens S, Rotshtein P, Ohman A, and Dolan RJ, 2004. Neural systems supporting interoceptive awareness. Nature Neuroscience 7:189-195.

Danilova V and Hellekant G, 2002. Oral sensation of ethanol in primate model III: Responses in the lingual branch of the trigeminal nerve of Macaca mulatta. Alcohol 26:3-16.

de Araujo IET and Rolls ET, 2004. The representation in the human brain of food texture and oral fat. Journal of Neuroscience 24:3086-3093.

de Araujo IET, Kringelbach ML, Rolls ET, and Hobden P, 2003a. The representation of umami taste in the human brain. Journal of Neurophysiology 90:313-319.

de Araujo IET, Kringelbach ML, Rolls ET, and McGlone F, 2003b. Human cortical responses to water in the mouth, and the effects of thirst. Journal of Neurophysiology 90:1865-1876.

de Araujo IET, Rolls ET, Kringelbach ML, McGlone F, and Phillips N, 2003c. Taste-olfactory convergence, and the representation of the pleasantness of flavour, in the human brain. European Journal of Neuroscience 18:2374-2390.

Forss DA, 1972. Odor and flavor compounds from lipids. Progress in the Chemistry of Fats and Other Lipids 13:177-258.

Francis S, Rolls ET, Bowtell R, McGlone F, O'Doherty J, Browning A, Clare S, and Smith E, 1999. The representation of pleasant touch in the brain and its relationship with taste and olfactory areas. NeuroReport 10:453-459.

Friedman DP, Murray EA, O’Neill JB, and Mishkin M, 1986. Cortical connections of the somatosensory fields of the lateral sulcus of macaques: Evidence for a corticolimbic pathway for touch. Journal of Comparative Neurology 252:323-347. 
Gilbertson TA, 1998. Gustatory mechanisms for the detection of fat. Current Opinion in Neurobiology 8:447-452.

Gilbertson TA, Fontenot DT, Liu L, Zhang H, and Monroe WT, 1997. Fatty acid modulation of K+ channels in taste receptor cells: Gustatory cues for dietary fat. American Journal of Physiology 272:C1203-C1210.

Grabenhorst F and Rolls ET, 2008. Selective attention to affective value alters how the brain processes taste stimuli. European Journal of Neuroscience 27:723-729.

Grabenhorst F, Rolls ET, and Bilderbeck A, 2008. How cognition modulates affective responses to taste and flavor: Top down influences on the orbitofrontal and pregenual cingulate cortices. Cerebral Cortex 18:1549-1559.

Guest S, Grabenhorst F, Essick G, Chen Y, Young M, McGlone F, de Araujo I, and Rolls ET, 2007. Human cortical representation of oral temperature. Physiology and Behavior 92:975-984.

Jain N, Qi H-X, Catania KC, and Kaas JH, 2001. Anatomic correlates of the face and oral cavity representations in the somatosensory cortical area $3 \mathrm{~b}$ of monkeys. Journal of Comparative Neurology 429:455-468.

Kadohisa M, Rolls ET, and Verhagen JV, 2004. Orbitofrontal cortex neuronal representation of temperature and capsaicin in the mouth. Neuroscience 127:207-221.

Kadohisa M, Rolls ET, and Verhagen JV, 2005a. Neuronal representations of stimuli in the mouth: The primate insular taste cortex, orbitofrontal cortex, and amygdala. Chemical Senses 30:401-419.

Kadohisa M, Rolls ET, and Verhagen JV, 2005b. The primate amygdala: Neuronal representations of the viscosity, fat texture, temperature, grittiness and taste of foods. Neuroscience 132:33-48.

Kringelbach ML, O'Doherty J, Rolls ET, and Andrews C, 2003. Activation of the human orbitofrontal cortex to a liquid food stimulus is correlated with its subjective pleasantness. Cerebral Cortex 13:1064-1071.

Manger PR, Woods TM, and Jones EG, 1996. Representation of face and intra-oral structures in area $3 \mathrm{~b}$ of macaque monkey somatosensory cortex. Journal of Comparative Neurology 371:513-521.

Maruyama Y, Pereira E, Margolskee RF, Chaudhari N, and Roper SD, 2006. Umami responses in mouse taste cells indicate more than one receptor. Journal of Neuroscience 26:2227-2234.

McCabe C and Rolls ET, 2007. Umami: A delicious flavor formed by convergence of taste and olfactory pathways in the human brain. European Journal of Neuroscience 25:1855-1864.

McCabe C, Rolls ET, Bilderbeck A, and McGlone F, 2008. Cognitive influences on the affective representation of touch and the sight of touch in the human brain. Social, Cognitive and Affective Neuroscience 3:97-108.

Mela DJ, 1988. Sensory assessment of fat content in fluid dairy products. Appetite 10:37-44.

Mufson EJ and Mesulam M-M, 1982. Insula of the old world monkey II: Afferent cortical input and comments on the claustrum. Journal of Comparative Neurology 212:23-37.

O’Doherty J, Rolls ET, Francis S, Bowtell R, McGlone F, Kobal G, Renner B, and Ahne G, 2000. Sensory-specific satiety related olfactory activation of the human orbitofrontal cortex. NeuroReport 11:893-897.

O'Doherty J, Rolls ET, Francis S, Bowtell R, and McGlone F, 2001. The representation of pleasant and aversive taste in the human brain. Journal of Neurophysiology 85:1315-1321.

Ogawa H, Sato M, and Yamashita S, 1968. Chorda tympani fibres of the rat and hamster to gustatory and thermal stimuli. Journal of Neurophysiology 199:223-240.

Poellinger A, Thomas R, Lio P, Lee A, Makris N, Rosen BR, and Kwong KK, 2001. Activation and habituation in olfaction- an fMRI study. NeuroImage 13:547-560. 
Pritchard TC, Hamilton RB, and Norgren R, 1989. Neural coding of gustatory information in the thalamus of Macaca mulatta. Journal of Neurophysiology 61:1-14.

Rodriguez S, Warren CS, Moreno S, Cepeda-Benito A, Gleaves DH, Del Carmen Fernandez $\mathrm{M}$, and Vila J, 2007. Adaptation of the food-craving questionnaire trait for the assessment of chocolate cravings: Validation across British and Spanish Women. Appetite 49:245-250.

Rolls ET, 1996. The orbitofrontal cortex. Philosophical Transactions of the Royal Society of London B 351:1433-1444.

Rolls ET, 1997. Taste and olfactory processing in the brain and its relation to the control of eating. Critical Reviews in Neurobiology 11:263-287.

Rolls ET, 1998. Taste and olfactory processing in the brain, and its relation to the control of eating. Frontiers of Oral Biology 9:40-75.

Rolls ET, 1999. The Brain and Emotion. Oxford: Oxford University Press.

Rolls ET, 2000a. Taste, olfactory, visual and somatosensory representations of the sensory properties of foods in the brain, and their relation to the control of food intake. In: Neural and Metabolic Control of Macronutrient Intake (Berthoud H-R, Seeley RJ, eds.), pp. 247-262. Boca-Raton, FL: CRC Press.

Rolls ET, 2000b. The orbitofrontal cortex and reward. Cerebral Cortex 10:284-294.

Rolls ET, 2000c. Neurophysiology and functions of the primate amygdala, and the neural basis of emotion. In: The Amygdala: A Functional Analysis, 2nd edn. (Aggleton JP, ed.), pp. 447-478. Oxford: Oxford University Press.

Rolls ET, 2001. The rules of formation of the olfactory representations found in the orbitofrontal cortex olfactory areas in primates. Chemical Senses 26:595-604.

Rolls ET, 2002a. The functions of the orbitofrontal cortex. In: Principles of Frontal Lobe Function (Stuss DT, Knight, R.T., ed.), Chapter 23, pp. 354-375. New York: Oxford University Press.

Rolls ET, 2002b. The cortical representation of taste and smell. In: Olfaction, Taste and Cognition (Rouby G, Schaal B, Dubois D, Gervais R, Holley A, eds.), pp. 367-388. New York: Cambridge University Press.

Rolls ET, 2005. Emotion Explained. Oxford: Oxford University Press.

Rolls ET, 2007. Sensory processing in the brain related to the control of food intake. Proceedings of the Nutrition Society 66:96-112.

Rolls ET, 2008a. The anterior and midcingulate cortices and reward. In: Cingulate Neurobiology \& Disease (Vogt BA, ed.). Oxford: Oxford University Press.

Rolls ET, 2008b. Functions of the orbitofrontal and pregenual cingulate cortex in taste, olfaction, appetite and emotion. Acta Physiologica Hungarica 95:131-164.

Rolls ET, 2008c. Memory, Attention, and Decision-Making: A Unifying Computational Neuroscience Approach Oxford: Oxford University Press.

Rolls ET and Baylis LL, 1994. Gustatory, olfactory, and visual convergence within the primate orbitofrontal cortex. Journal of Neuroscience 14:5437-5452.

Rolls ET and Deco G, 2002. Computational Neuroscience of Vision. Oxford: Oxford University Press.

Rolls ET and Grabenhorst F, 2008. The orbitofrontal cortex and beyond: From affect to decision-making. Progress in Neurobiology 86:216-244.

Rolls ET and McCabe C, 2007. Enhanced affective brain representations of chocolate in cravers vs non-cravers. European Journal of Neuroscience 26:1067-1076.

Rolls ET and Rolls BJ, 1977. Activity of neurones in sensory, hypothalamic and motor areas during feeding in the monkey. In: Food Intake and Chemical Senses (Katsuki Y, Sato M, Takagi S, Oomura Y, eds.), pp. 525-549. Tokyo: University of Tokyo Press.

Rolls ET and Rolls BJ, 1982. Brain mechanisms involved in feeding. In: Psychobiology of Human Food Selection (Barker LM, ed.), pp. 33-62. Westport, CT: AVI Publishing Company. 
Rolls ET and Scott TR, 2003. Central taste anatomy and neurophysiology. In: Handbook of Olfaction and Gustation, 2nd edn. (Doty RL, ed.), pp. 679-705. New York: Dekker.

Rolls BJ, Rolls ET, Rowe EA, and Sweeney K, 1981a. Sensory specific satiety in man. Physiology and Behavior 27:137-142.

Rolls BJ, Rowe EA, Rolls ET, Kingston B, Megson A, and Gunary R, 1981b. Variety in a meal enhances food intake in man. Physiology and Behavior 26:215-221.

Rolls BJ, Rowe EA, and Rolls ET, 1982. How sensory properties of foods affect human feeding behavior. Physiology and Behavior 29:409-417.

Rolls BJ, Rolls ET, and Rowe EA, 1983a. Body fat control and obesity. Behavioral and Brain Sciences 4:744-745.

Rolls ET, Rolls BJ, and Rowe EA, 1983b. Sensory-specific and motivation-specific satiety for the sight and taste of food and water in man. Physiology and Behavior 30:185-192.

Rolls ET, Murzi E, Yaxley S, Thorpe SJ, and Simpson SJ, 1986. Sensory-specific satiety: Food-specific reduction in responsiveness of ventral forebrain neurons after feeding in the monkey. Brain Research 368:79-86.

Rolls ET, Scott TR, Sienkiewicz ZJ, and Yaxley S, 1988. The responsiveness of neurones in the frontal opercular gustatory cortex of the macaque monkey is independent of hunger. Journal of Physiology 397:1-12.

Rolls ET, Sienkiewicz ZJ, and Yaxley S, 1989. Hunger modulates the responses to gustatory stimuli of single neurons in the caudolateral orbitofrontal cortex of the macaque monkey. European Journal of Neuroscience 1:53-60.

Rolls ET, Yaxley S, and Sienkiewicz ZJ, 1990. Gustatory responses of single neurons in the caudolateral orbitofrontal cortex of the macaque monkey. Journal of Neurophysiology 64:1055-1066.

Rolls ET, Critchley HD, Mason R, and Wakeman EA, 1996a. Orbitofrontal cortex neurons: Role in olfactory and visual association learning. Journal of Neurophysiology 75:1970-1981.

Rolls ET, Critchley H, Wakeman EA, and Mason R, 1996b. Responses of neurons in the primate taste cortex to the glutamate ion and to inosine $5^{\prime}$-monophosphate. Physiology and Behavior 59:991-1000.

Rolls ET, Critchley HD, Browning A, and Hernadi I, 1998. The neurophysiology of taste and olfaction in primates, and umami flavor. Annals of the New York Academy of Sciences 855:426-437.

Rolls ET, Critchley HD, Browning AS, Hernadi A, and Lenard L, 1999. Responses to the sensory properties of fat of neurons in the primate orbitofrontal cortex. Journal of Neuroscience 19:1532-1540.

Rolls ET, Kringelbach ML, and de Araujo IET, 2003a. Different representations of pleasant and unpleasant odors in the human brain. European Journal of Neuroscience 18:695-703.

Rolls ET, Verhagen JV, and Kadohisa M, 2003b. Representations of the texture of food in the primate orbitofrontal cortex: Neurons responding to viscosity, grittiness and capsaicin. Journal of Neurophysiology 90:3711-3724.

Rolls ET, O’Doherty J, Kringelbach ML, Francis S, Bowtell R, and McGlone F, 2003c. Representations of pleasant and painful touch in the human orbitofrontal and cingulate cortices. Cerebral Cortex 13:308-317.

Rolls ET, Grabenhorst F, and Parris BA, 2008a. Warm pleasant feelings in the brain. Neuroimage 41:1504-1513.

Rolls ET, Grabenhorst F, Margot C, da Silva MAAP, and Velazco MI, 2008b. Selective attention to affective value alters how the brain processes olfactory stimuli. Journal of Cognitive Neuroscience 20:1815-1826.

Sato M, Ogawa H, and Yamashita S, 1975. Response properties of macaque monkey chorda tympani fibers. Journal of General Physiology 66:781-821. 
Scott TR, Yaxley S, Sienkiewicz ZJ, and Rolls ET, 1986. Gustatory responses in the frontal opercular cortex of the alert cynomolgus monkey. Journal of Neurophysiology 56:876-890.

Scott TR, Yan J, and Rolls ET, 1995. Brain mechanisms of satiety and taste in macaques. Neurobiology 3:281-292.

Small DM and Prescott J, 2005. Odor/taste integration and the perception of flavor. Experimental Brain Research 166:345-357.

Small DM, Zald DH, Jones-Gotman M, Zatorre RJ, Pardo JV, Frey S, and Petrides M, 1999. Human cortical gustatory areas: A review of functional neuroimaging data. NeuroReport 10:7-14.

Small DM, Voss J, Mak YE, Simmons KB, Parrish T, and Gitelman D, 2004. Experiencedependent neural integration of taste and smell in the human brain. Journal of Neurophysiology 92:1892-1903.

Sobel N, Prabkakaran V, Zhao Z, Desmond JE, Glover GH, Sullivan EV, and Gabrieli JDE, 2000. Time course of odorant-induced activation in the human primary olfactory cortex. Journal of Neurophysiology 83:537-551.

Verhagen JV, Rolls ET, and Kadohisa M, 2003a. Neurons in the primate orbitofrontal cortex respond to fat texture independently of viscosity. Journal of Neurophysiology 90:1514-1525.

Verhagen JV, Giza BK, and Scott TR, 2003b. Responses to taste stimulation in the ventroposteromedial nucleus of the thalamus in rats. Journal of Neurophysiology 89:265-275.

Verhagen JV, Kadohisa M, and Rolls ET, 2004. The primate insular/opercular taste cortex: Neuronal representations of the viscosity, fat texture, grittiness, temperature and taste of foods. Journal of Neurophysiology 92:1685-1699.

Yaxley S, Rolls ET, Sienkiewicz ZJ, and Scott TR, 1985. Satiety does not affect gustatory activity in the nucleus of the solitary tract of the alert monkey. Brain Research 347:85-93.

Yaxley S, Rolls ET, and Sienkiewicz ZJ, 1988. The responsiveness of neurons in the insular gustatory cortex of the macaque monkey is independent of hunger. Physiology and Behavior 42:223-229.

Yaxley S, Rolls ET, and Sienkiewicz ZJ, 1990. Gustatory responses of single neurons in the insula of the macaque monkey. Journal of Neurophysiology 63:689-700.

Zald DH and Pardo JV, 1997. Emotion, olfaction, and the human amygdala: Amygdala activation during aversive olfactory stimulation. Proceedings of the National Academy of Sciences USA 94: 4119-4124.

Zald DH, Lee JT, Fluegel KW, and Pardo JV, 1998. Aversive gustatory stimulation activates limbic circuits in humans. Brain 121:1143-1154.

Zatorre RJ, Jones-Gotman M, Evans AC, and Meyer E, 1992. Functional localization of human olfactory cortex. Nature 360:339-340.

Zatorre RJ, Jones-Gotman M, and Rouby C, 2000. Neural mechanisms involved in odour pleasantness and intensity judgements. NeuroReport 11:2711-2716.

Zhao GQ, Zhang Y, Hoon MA, Chandrashekar J, Erlenbach I, Ryba NJ, and Zuker CS, 2003. The receptors for mammalian sweet and umami taste. Cell 115:255-266. 
